\title{
Telenovela, política y redes sociales: lecturas de La Leona
}

\section{Telenovela, política e redes sociais: leituras de La}

\section{Leona}

Libertad Borda

Resumen: En un panorama adverso para la televisión abierta, la telenovela argentina intenta sobrevivir recurriendo, por una parte, a su raigambre melodramática, $y$, por otra, a su característica porosidad hacia el contexto social e incluso político. La leona, producida en 2015 pero emitida en 2016, es un ejemplo de cómo el género puede tensionar uno de sus pilares, la historia de amor, para poner en el centro del relato un conflicto entre obreros y empresarios. Este artículo se propone indagar las evaluaciones de La leona que publicaron los y las televidentes en distintas redes sociales durante su emisión, y cómo estas lecturas se diferenciaron en tanto consideraban a la telenovela como un exponente de un género con sus correspondientes reglas o como una alegoría de determinada situación sociopolítica.

Palabras clave: fans; telenovela; televisión.

Abstract: In an unfavourable scene for broadcast television, Argentinian telenovela struggles to survive by drawing on its melodramatic roots on the one hand, and on its typical permeability to the social or even political context, on the other. La leona, produced in 2015 but broadcast in 2016, is an example of how this genre can marginalize one of its main pillars, the love story, to focus the narrative on a workplace conflict between workers and employers. This article intends to analyze the evaluations of La leona posted by viewers in various social networks

1 Universidad de Buenos Aires (UBA). Buenos Aires, BA, Argentina.

https://orcid.org/0000-0002-2511-3402 E-mail: libertadborda@gmail.com 
during its running period, and how these readings were different insofar as they considered the telenovela either as an exponent of a genre, with its corresponding rules, or as an allegory of a certain sociopolitical situation.

Keywords: fans; telenovela; televisión. 


\section{Introducción: la telenovela ante un escenario audiovisual cambiante}

En sus casi setenta años de existencia, la telenovela latinoamericana ha recibido más de una vez diagnósticos agoreros con distintos argumentos. Entre ellos, surge hoy un dato objetivo: han aparecido rivales insospechados hace dos décadas, como Turquía y sus producciones de gran presupuesto, con un star system por descubrir e historias que retrotraen a los personajes femeninos al lugar de vulnerabilidad extrema. Sin embargo, no es la primera vez que este género ha tenido que competir con productos de otras latitudes y siempre pudo resurgir. La diferencia del contexto actual es que la agonía no sólo se le adjudica por un descenso en la calidad de las historias -afirmación que insistía en otros tiempos- o en el presupuesto invertido en comparación con las extranjeras, sino que le llegaría por tratarse de un género de la televisión abierta. Es la televisión abierta la que estaría en jaque según muchos indicios: a las ofertas del cable se suman las nuevas plataformas de streaming como Netflix y Hulu, y las propuestas de fuentes no tradicionales como los llamados youtubers. ${ }^{2}$

A pesar de esta situación adversa, para resistir a la muerte anunciada la telenovela recurre a dos de sus pilares más notables: su raigambre melodramática y su porosidad narrativa, que le habilita la incorporación de otros géneros como el policial, el realismo social, la publicidad, o incluso su tramado con discursos como el médico y el periodístico. Entre otras cuestiones es esta porosidad la que le ha permitido, en distintos períodos de la trayectoria del género, tensionar el equilibrio entre el verosímil social y el de género para dar lugar a variaciones estilísticas. Así, en la Argentina de los setenta, el autor Alberto Migré consolidó con Rolando Rivas, taxista (1972-1973) una fórmula en la que el verosímil social avanzaba sobre el de género en ciertas zonas de la historia, en las que la telenovela se abría a conflictos de la realidad contemporánea.

2 Según Kantarlbope el share de los cinco canales de televisión abierta argentina descendió un $11 \%$ desde 2011 y el rating promedio, que era de 39,1 en 2004, fue de 26,1 en 2016 (RIVERO, 2017). 
Este estilo es en gran medida desplazado en la producción argentina de los noventa en favor de un modelo despegado de localismos explícitos en función de la fiebre de exportación de esos años. A fines de esa década resurgen las referencias a la realidad local acompañadas de un remozado costumbrismo, sobre todo de la mano de la productora de contenidos Pol-ka ${ }^{3}$, pero es hacia mediados del 2000 donde vuelve a manifestarse mucho más claramente un avance del verosímil social en una reconfiguración del género con textos en los que se destaca el protagonismo masculino, la presencia de villanos cuyos delitos afecten a la sociedad toda, un relegamiento de los conflictos de clase o económicos y la justicia como eje de las acciones (BOURDIEU, 2008). Por ejemplo, Resistiré (2003) y Vidas robadas (2008) tematizaban respectivamente el tráfico de sangre y la trata de personas. En Montecristo (2006) se logró, por primera vez, conectar la tradicional búsqueda de la identidad escamoteada en el melodrama con la problemática del robo de bebés durante la dictadura, en un contexto político que habilitaba esta inclusión narrativa (MAZZIOTTI, 2006a), dado que el gobierno del Presidente Néstor Kirchner, así como el de Cristina Fernández que le sucedió, mantuvieron un diálogo estrecho con los organismos de derechos humanos y apoyaron los así llamados Juicios por la Memoria, la Verdad y la Justicia ${ }^{4}$.

En 2016, ya en otro contexto político, se estrenó La Leona, una telenovela que marcaba continuidades y quiebres con este nuevo estilo, ya que se hacía cargo de problemas de la realidad social contemporánea y ponía todo el acento en la justicia, pero a la vez se anunciaba como una historia de lucha sindical con una protagonista femenina fuerte.

Las nuevas posibilidades que tienen los televidentes desde hace ya muchos años de comentar lo visto en las redes sociales permiten a la mirada analítica no sólo abordar la textualidad del recorte propuesto sino

3 Pol-ka produjo títulos que retomaban rasgos costumbristas a la vez que oscilaban entre la telenovela y la telecomedia, como es el caso de Gasoleros (1998-99), El sodero de mi vida (2001-2002) o Sos mi vida (2006) entre muchas otras.

4 Se llama Procesos por la Memoria, la Verdad y la Justicia a los juicios llevados a cabo contra los responsables de violaciones a los derechos humanos acaecidos durante la dictadura cívico-militar en Argentina en el período 1976-1983. 
también las interpretaciones y posturas de los miembros de la audiencia que glosan sus consumos en las plataformas digitales. La pregunta que guía este trabajo, entonces, se aboca a indagar cómo fue interpretada esta labilidad del género telenovela en el caso de La Leona, y cómo la porosidad incluso abarcó el contexto de producción previo al estreno.

\section{La leona: en el principio fue el boicot}

La leona. De pasión, amor y lucha, reúne varios elementos que la hacen si no única, por lo menos destacable: el contexto político peculiar que rodeó su estreno, un guion que emprendió caminos insospechados para el género y un público que aprovechó a fondo las posibilidades que dan las redes sociales para vocear su adhesión o su rechazo.

A diferencia de lo habitual según el modelo de producción del género, La leona, tercera telenovela producida por El árbol ${ }^{5}$-en este caso conjuntamente con Telefe contenidos- fue escrita y grabada casi en su totalidad durante 2015, pero recién comenzó a emitirse, por la pantalla del canal argentino de televisión abierta Telefe a las 22, el 18 de enero de 2016, en la que permaneció hasta el 14 de julio de ese año.

Pero una peculiaridad más prominente aún es la polémica que se desencadenó antes de la emisión, a mediados de diciembre de 2015, cuando desde las redes sociales -es decir, sin una autoría claramente identificable- se lanzó una campaña de boicot contra la telenovela. Esto permite anticipar una de las lecturas posibles del texto, que excedía incluso su trama: el consumo de la telenovela fue representado como coherente con el alineamiento con la línea política de sus protagonistas, los actores Pablo Echarri -también socio productor- y Nancy Dupláa, ambos identificados públicamente con el kirchnerismo, es decir, con la política llevada a cabo por los gobiernos de Néstor Kirchner y Cristina Fernández de Kirchner (2003-2007 y 2007-2015, respectivamente). Desde esta óptica simplista, si no se era "K" -es decir, kirchnerista-, no sólo no se podía mirar la telenovela sino que se alentaba a boicotearla.

5 La productora El Árbol fue creada en 2010 por Pablo Echarri, Martín Seefeld y RonnieAmendolara. En mayo de este año Echarri anunció la disolución de la sociedad. 
La virulencia de los mensajes de aquellos que apoyaron la campaña adhiriendo a los hashtags \#DecileNoALaNovelaLaLeona, \#DecileNoALaLeona y \#NoaLaLeona, así como la intensa productividad textual que desplegaron los detractores en las redes, permiten pensar a esta corriente contraria al estreno como una verdadera práctica antifan. ${ }^{6}$ Sin embargo, a diferencia de otros casos en los que el desprecio o el odio está sustentado en la supuesta inferioridad estética de la figura en cuestión, en éste -aunque la "mala calidad" era también un argumento esgrimido- el mayor acento se colocaba en las acusaciones de "robar dinero público" gracias a la proximidad con la gestión estatal saliente:

@telefe_com váyanse a cagar!!! Novela paga con MIS IMPUESTOS!! \#burros \#NoALaLeona (19/01/16).

Esa gentuza $\mathrm{NO}$ merecen respeto xq en década $\mathrm{K}$ se cagaron en todos (18/01/16).

A tal punto llegó la intensidad de la campaña que el mismo día en que se estrenaba La leona el propio presidente de la Nación, Mauricio Macri, intervino con un tuit en el que intentaba calmar las aguas: "Suerte a Pablo Echarri y al equipo de \#LaLeona en su estreno. No creo en boicots a ninguna expresión cultural. Unamos a la Argentina”. No obstante, los tuits boicoteadores siguieron publicándose durante toda la emisión, aunque con menor intensidad que en esas primeras semanas.

Por un tiempo, el programa intentó dar la pelea por el primer lugar en el rating del prime time, rivalizando con Los ricos no piden permiso, de la productora local Pol-ka, emitida por Canal 13. Sin embargo, ante el rating mucho mayor obtenido por producciones de otros países, como la turca ¿Qué culpa tiene Fatmagül?,o, al finalizar aquella en marzo, la brasileña Moisés y los diez mandamientos. ambos por Telefe, la obsesión de este canal por obedecer el mandato de las mediciones llevó a desplazar a La leona sucesivamente a las 22.15, a las 22.30, a

6 Los así llamados antifans son algo así como el espejo invertido de los fans en tanto no los motiva la afinidad sino el disgusto o incluso el odio (Johnson, 2007). 
las 23 y a las 23.30 horas. Los últimos capítulos, para desesperación de los fans que voceaban su queja en Twitter y Facebook, se emitieron casi a las 23.50. A pesar de tantos cambios, la telenovela logró retener un promedio de entre 10 y 12 puntos de rating, lejos de los picos de 17 en su debut, pero notable para un horario ingrato. Y es que, en el transcurso de los seis meses que duró la emisión de La leona, el insistente rumor en las redes venía dando evidencias de que "la novela de Echarri y Dupláa” iba consolidando un público fiel, que la seguía a pesar de los cambios de horario, o que optaba directamente por verla online a través de la página web de Telefe o bien de los videos subidos por fans en Youtube. Es evidente que, más allá del contexto polémico que rodeó su estreno, La leona tenía en su factura misma componentes que explicaban el fervor de sus fans.

\section{Una historia diferente}

La leona cuenta la historia de María Leone, una obrera de la Textil Liberman, que vive en una casa del barrio La Hilada, creado para los trabajadores de la fábrica, junto con sus padres y hermana, y su marido Fabián, padre biológico de su segundo hijo y de crianza del primero. Salvo algún resentimiento fugaz, se pinta a los obreros como trabajadores dedicados, que eligen celebrar todo lo que consideran un pequeño o gran triunfo: el cobro del sueldo después de un retraso patronal, uno de los obreros se recibe de abogado tras años de esfuerzo, o festejar el cumpleaños de la hija del delegado en la fábrica porque no se pudo llegar a pagar el salón.

En la vereda de enfrente, y en contraste con los luminosos Leone, la complicada familia Miller-Liberman: Diana Liberman (Esther Goris), nieta del fundador, casada con Klaus Miller (Miguel Ángel Solá), hoy el dueño de la textil, y sus hijos, Gabriel (Rodrigo Gil Navarro), enamorado eterno de María que paulatinamente se irá mostrando como una persona violenta y capaz de matar, y Brian (Peter Lanzani), adicto y traumatizado por la relación incestuosa con su madre. 
Klaus Miller, consciente de que tiene una enfermedad terminal, se propone pasar los últimos meses de vida disfrutando de su dinero con su amante joven, gracias a una quiebra fraudulenta que perjudicará a los obreros y también a su propia familia. Para lograrlo contrata a Franco Uribe (Pablo Echarri) y su equipo, expertos en desguace de empresas. Sin embargo, Franco tiene su propia agenda. Quiere vengarse de su padre, no otro que Klaus, quien tuvo una aventura con su madre, Sofía, y los repudió a ambos. Miller, por supuesto, ignora la identidad real de Uribe. Con el correr de los capítulos la audiencia se entera de que Sofía es en verdad Sara Liberman, hermana gemela de Ruth, la madre biológica de Franco.

Franco quiere recuperar la fábrica sobre la que tiene derechos como hijo de Miller, pero su plan de venganza se dificulta al conocer a María y enamorarse de ella. Una vez más, la vieja historia del amor imposible: él viene a vaciar la fábrica y hacerles la vida muy difícil a los obreros, aunque no deja de desear a María y admirar su valentía; ella sabe que Franco está en el bando contrario y eso le genera desconfianza, pero también se siente fuertemente atraída hacia él. La postura ambigua de este galán atípico lo lleva, por ejemplo, a comunicar al respetado patriarca, Pedro Leone, que está despedido, lo cual le produce la muerte por un ataque cardíaco.

Como terceros en discordia: Gabriel Miller y Julieta Irigoyen, socia de Uribe. Ambos tratarán de separar a la pareja central, pero las diferencias que alejan a María y Franco son, antes que nada, posiciones opuestas en la lucha que enfrenta a obreros y patronal.

A pesar de la postura tibia del sindicato involucrado, los trabajadores se van organizan, ocupan la textil y, ante la declaración final de quiebra, deciden intentar constituir una "fábrica recuperada", expresión que en Argentina refiere a las empresas gestionadas por sus trabajadores mediante cooperativas de trabajo luego de una quiebra.

Mientras tanto, Franco ha revelado su verdadera identidad y ha conocido aquellos datos que ignoraba: que la que creía su madre es su tía, y que su padre intentó matarlo al nacer por una promesa hecha a Diana, 
la hermana Liberman que siempre lo amó y le prometió la fábrica a cambio de estar a su lado.

Luego de muchos avatares, los obreros, ahora miembros de la Cooperativa "Trabajo Argentino", logran que el proyecto de expropiación de la textil sea debatido y aprobado en la legislatura. Franco, ya redimido de su odio, facilita como heredero que el proceso sea más fluido, pero cuando María se entera de esta intervención, ya es tarde, él se ha ido.

Durante un año, ella se dedica a viajar por el país enseñando a otros trabajadores el proyecto de la cooperativa Trabajo Argentino. En medio de un festejo de carnaval en Purmamarca (Provincia de Jujuy), se reencuentra con Franco-Diego (su verdadero nombre) y reanudan la historia de amor.

¿Qué quedó de la vieja telenovela argentina melodramática y a la vez costumbrista (MAZZIOTTI, 1993) en esta historia atípica? Sin duda, está el sufrimiento excesivo, desbordado, pero ya desplazado de su foco habitual en los desengaños amorosos se apoya en otros tópicos: los despidos injustos, las muertes de los buenos. A María, por más que sufre primero con la actitud de Franco de perjudicar a los obreros y luego con su alejamiento, la vemos llorar más que nunca con la muerte de su padre.

El cortejo fúnebre de Pedro Leone fue un ejemplo paradigmático de melodrama puro y duro, alejado del uso paródico al que tienden algunas producciones de Televisa o Telemundo: el coche que lleva el cuerpo avanza lentamente, acompañado por la tristísima música del cantautor Gabo Ferro: "Frío, hace tanto frío, que no puedo más que arder...". Al mismo tiempo, la policía intenta desalojar la fábrica, tomada por los obreros. María Leone, a la cabeza de la protesta, recibe palos ante la mirada desesperada del galán: él no ordenó el desalojo sino el verdadero villano, Klaus. Pero el cortejo llega ante las puertas de la textil y el sufrimiento de la violencia represiva da lugar al otro pesar, más íntimo, del llanto por la muerte del ser querido. Sin embargo, María elige quedarse en la fábrica y no ir al entierro, con lo cual se subraya, una vez más, el foco de la historia. De todos modos, nadie en la audiencia, por 
más cínico y endurecido que sea, queda a salvo de las lágrimas: no hay cómo ver esta escena irónicamente. ${ }^{7}$

En la línea de las continuidades, se insiste en el mundo social bipolar de la tradición del melodrama argentino. Un mundo en el que los ricos son fríos, egoístas y disociados de todo sentimiento nacional, y los pobres son solidarios, espontáneos, sinceros y auténticos, en suma, superiores en términos morales. Los Leone y los Miller-Liberman son continuidad de este universo partido.

El tópico melodramático del "drama del reconocimiento", por otro lado, se verá en su costado más tradicional en la identidad escamoteada de Franco, mientras que en el caso de María se juega de un modo innovador: no hay dudas sobre quién es su padre, pero también se observa un proceso de reconocimiento. Ella será confirmada como líder con su nombramiento como presidenta de la cooperativa, no por inteligencia ni formación universitaria sino por su compañerismo, lealtad y coraje.

Justamente es en la construcción de la heroína donde existe una ruptura mayor: María pertenece al mundo de las heroínas fuertes que en los noventa en Argentina comenzaron a delinear Andrea del Boca y Luisa Kulliok y quedaron relegadas en las telenovelas de protagonismo masculino mencionadas. Pero a diferencia de aquellas, no se la verá devastada por el abandono de un hombre. En una escena reveladora dice, mirando una foto de Uribe en una de las oficinas de la fábrica tomada: "Me hubiera animado a tanto con vos... y bueno, ;fuiste!", al tiempo que suena el verso "ojalá pase algo que te borre de pronto" de la canción de Silvio Rodríguez. Por más que el sufrimiento atroz es ley del melodrama, todos los espectadores advierten que María no va a enfermarse de amor, hay demasiado para hacer. Aquí el texto se acerca riesgosamente al límite del género y, como se verá más adelante, éste tal vez fue el punto más polémico de La leona: ¿es posible una telenovela en la que el amor no sea lo más importante?

7 “Tiemblo y lloro por la muerte de Pedro Leone (La Leona) como si me hubiera sucedido a mi”, dice un comentario en el sitio Resistiendo con Aguante (ver Corpus). La escena puede verse en https://www.youtube.com/watch?v=zV-zdqhE0As. 
En efecto, una de las pocas críticas negativas que se realizaron en la prensa de espectáculos, en general muy elogiosa con La leona, tuvo que ver con la relativa marginalidad de la historia de amor respecto de la trama sindical. Aunque con más precisión podría decirse que se plantearon dudas respecto de la eficacia de este camino. En cambio, la construcción del personaje de María fue lo que más destacaron dichas críticas, que en muchos casos sostenían que, sin dejar de ser una telenovela, La leona era un producto transgresor en muchos sentidos, al punto de que en algunos casos fue saludado con frases que fueron desde "una gran novela" o "una de las ficciones más interesantes", hasta "la Rolando Rivas del siglo XXI".

Otra zona de la crítica especializada, en lugar de indagar las continuidades y rupturas respecto del género más bien subrayó el aspecto realista del relato, es decir, su mayor o menor adecuación a la realidad extratelevisiva: el barrio de La Hilada fue, en esta interpretación, la realidad de muchos barrios obreros argentinos en el pasado y el vaciamiento empresarial y los despidos vuelven a ser noticia en el presente ${ }^{10}$. Esta mirada, que se encuentra en diarios opositores al gobierno del Presidente Macri, como Páginal2, Tiempo Argentino, o La Izquierda Diario, ubican a La leona en una serie más ideológica que genérica, lo cual será dicho explícitamente desde el título de otra crítica de Páginal2: "Un culebrón nacional y popular". ${ }^{11}$

En el siguiente apartado se analiza cómo estas dos tendencias identificadas en la crítica especializada se manifiestan también en el discurso de los y las televidentes.

8 "La leona: balance de una gran novela". La Nación, Buenos Aires, 15 de julio de 2016.

9 "Una leona que le puso el cuerpo a un género difícil". Ámbito financiero, Buenos Aires, 18 de julio de 2016

10 "Una historia de amor y luchas sociales". Tiempo Argentino, Buenos Aires, 24 de enero de 2016.

11 La calificación de "nacional y popular" en Argentina tiende a asociarse con el movimiento peronista, que se configura inicialmente en torno a Juan Domingo Perón en 1945, y continúa con enormes transformaciones hasta hoy. Explicar el alcance de esta expresión llevaría muchas páginas, y debería incluir antecedentes ineludibles como los gobiernos populares de Hipólito Yrigoyen (1916-1922; 1928-1930) pero en general refiere, entre otras cosas, a un modelo político que reivindica la justicia social, la soberanía política y la independencia económica. 


\section{Los ojos de los televidentes}

El análisis de los discursos de los espectadores que circularon en las redes sociales se basa en un corpus compuesto por publicaciones en los siguientes sitios o plataformas digitales:

1. Facebook:

Perfil personal del autor Pablo Lago. ${ }^{12}$

Grupo cerrado de fans: La leona

Grupo cerrado Resistiendo con Aguante

Fan Page La leona (oficial)

2. Twitter

Publicaciones con el hashtag \#LaLeona, \#DecileNoALaNovelaLaLeona, \#DecileNoALaLeona y \#NoaLaLeona

3. Foro AR-telenovelas (al que solo acceden los miembros): subforo de La leona

4. Youtube (comentarios a capítulos o partes de capítulos)

5. Comentarios a críticas en publicaciones online (La Nación, La Izquierda Diario, etc.)

En la transcripción de los posteos se respeta la ortografía y sintaxis original, pero para preservar la privacidad de los involucrados, no se publicará el nombre de usuario de los participantes.

$\mathrm{Al}$ igual que en los posicionamientos de la crítica de espectáculos ya señalados, un primer análisis de los discursos de televidentes permite observar que las miradas sobre el texto se realizan desde dos ángulos diferentes: algunos sitios o plataformas alojan lecturas realizadas desde el lugar de conocedores del género telenovela, mientras que otros, en cambio, disfrutan el texto exclusivamente por su perspectiva gremial o política.

En primer lugar, nos referiremos a las lecturas del texto dentro del marco genérico. Son las que podemos encontrar en sitios que los o las fans del género suelen frecuentar, como AR-telenovelas, un sitio de foros

12 Se cuenta con la autorización del autor para la cita de los posteos sin indicar la identidad de los comentaristas. 
que crea subforos de discusión para todos los títulos argentinos y algunos extranjeros particularmente exitosos. ${ }^{13} \mathrm{Si}$ bien ya no concitan una gran cantidad de miembros o publicaciones debido a la dispersión en otras modalidades de comunicación digital que anteriormente no se hallaban disponibles, como Facebook o Twitter, los foros de fans mantienen ciertas características en los modos de comunicación e interpretación de los textos:

a. Muchos de los seguidores deciden el consumo de una telenovela en función de consumos anteriores: son fans de un actor o actriz, de una productora, de un autor, etc. Por ejemplo, en el caso de AR-telenovelas, uno de los moderadores es ostensiblemente un/a $\mathrm{a}^{14}$ fan de Juan Gil Navarro, puesto que ostenta avatar y banner con la figura del actor.

b. Dicho conocimiento ayuda a evaluar o interpretar determinadas escenas o a imaginar posibles escenarios para los actores: "[la actriz Mónica] Antonópulos es ideal para este tipo de personajes”, se señala en un posteo, mientras que en otro alguien comenta que Dolores Fonzi "hubiera sido una excelente opción para una remake de Rubî”, en referencia a una telenovela mexicana de 2004, a lo que recibe como respuesta:

A mi Eugenia Leone me recuerda no solo a la ambiciosa Rubi sino a Rosario Moreno, personaje de Resistire interpretado por Romina Ricci. $(19 / 2 / 16)$

c. Dado que son fans del género telenovela, y ésta se caracteriza por contar una historia de amores difíciles (MAZZIOTTI, 1996), reclaman un lugar importante para la historia romántica, criterio central en su evaluación.

Fue una historia distinta, por eso el amor de los protagonistas quedó en... segundo plano??? $\bigcirc$ como en Vidas robadas, no? (15/7/16)

13 Para mayor información sobre el surgimiento de AR-telenovelas, véase BORDA, 2012.

14 El nickname (nombre del usuario) alude a una afición futbolística y no permite determinar el sexo. 
A mí me gusta asi como esta la novela centrada en el conflicto laboral y esa lucha. Porque disfruto de cada dialogo y esas grandes actuaciones. Pero reconozco que le esta faltando activar las historias de amor, sobre todo de los Maria y Franco - aunque en lo personal me atraparía la de Rodrigo y Eugenia-, porque es lo que pretende ver la mayoria del publico. $(24 / 2 / 16)$

Entiendo que es una novela centrada en conflictos sociales y lo respeto, pero hay mas escenas de Pedro y Sofía, Miller y su novia, Brian y Abril ( estos últimos dos me aburren mucho) que de Maria y Franco / Rodrigo y Eugenia(24/2/16)

El caso del grupo cerrado de Facebook ${ }^{15}$ y la fan page oficial presentan similitudes en las modalidades de recepción ${ }^{16}$ : las y los miembros recuerdan actuaciones pasadas de la pareja central o de otros actores y hasta incluso discuten la pericia de Echarri respecto de otro galán del género como Facundo Arana en lo que respecta al arte de besar en cámara:

A mi pablo me caliente con sólo verlo besar, me parece q cumple bien el rol de galán, además yo lo veo como un pibe de barrio y eso me gusta. Facundo no me transmite nada (17/7/16).

En segundo lugar me referiré a aquellas lecturas que tienden a realizarse desde fuera del marco genérico, y que en este caso pueden incluso preceder a la decodificación del texto en sí y situarse en la polémica -que antecedió a su emisión pero luego persistió con el correr de los capítulos- acerca de la filiación política de los actores protagónicos y en particular de Echarri, por ser uno de los socios de la productora de $L a$ leona.

15 En realidad existe por lo menos otro grupo en Facebook, en este caso público: Fanáticos de La leona. Elegimos el grupo La leona debido a que tanto la membrecía (alrededor de mil miembros frente a unos 200 en el otro caso) como la participación era mayor.

16 Si bien no es el objetivo entrar en detalle sobre las diferencias específicas entre cada uno de estos grupos, al menos se debe resaltar que en las fanpages los seguidores no pueden publicar mensajes salvo en la modalidad comentario, a diferencia de lo que sucede en los grupos, donde todos los mensajes tienen idéntica jerarquía. 
Estas lecturas políticas del texto abarcaron tanto el aliento a la pareja Dupláa/Echarri (“cumpas", "compañeros", "compañerazos”) a través de la publicación de fotos que recogían dichos de éstos relativos a la coyuntura política actual, como el elogio a la telenovela por poner en escena un conflicto sindical. Es el caso, sobre todo, de posteos en Resistiendo con aguante, un grupo cerrado de Facebook creado después de la derrota del kirchnerismo en las últimas elecciones con el lema "En este espacio resistimos contra el neoliberalismo", que en noviembre de 2017 contaba con más de medio millón de miembros.

La lucha representada en la ficción se interpretó en este grupo por lo general en forma alegórica, como si La leona no sólo hablara de un conflicto laboral sino, indirectamente, de uno más amplio, que implica enfrentamientos de largo alcance:

Gracias Leona por esta hermosa historia y este hermoso final, que nos define como argentinos...Gracias a todos los actores de la gran hostia que acompañaron mis noches de desvelo...

Trabajo, cultura, paisajes made in Argentina... Aguante la Industria Nacional, carajo! Los voy a extrañar!

“Tú no puedes comprar la lluvia, tú no puedes comprar el sol, tú no puedes comprar mi alegría, tú no puedes comprar mi ilusión..." ${ }^{17}$ Macri vende patria y lpmqtp!!! (15/7/16)

17 La cita remite a "Latinoamérica", la canción del grupo Calle 13 que fue uno de los temas que musicalizaron el último capítulo de la telenovela. 
Figura 1. Scena de La Leona

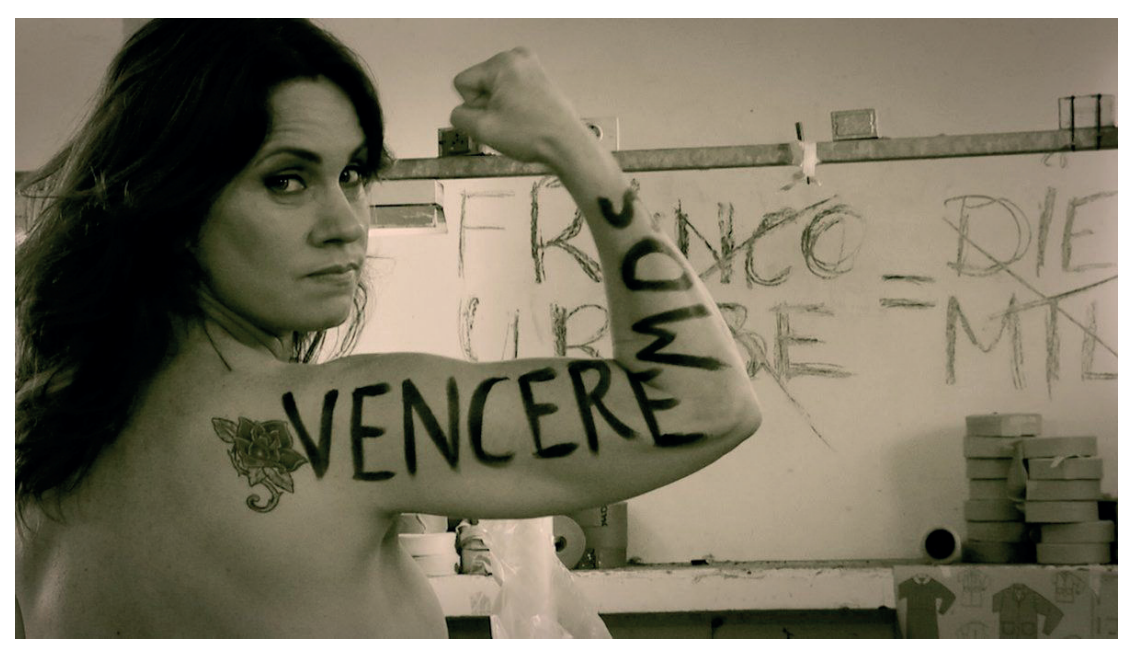

Fuente: la autora

El puño, los labios apretados, los ojos decididos: se respira determinación aunque la persona que mire la imagen no sepa de La leona y su historia. No es una musculatura trabajada. No es necesario un brazo de gimnasio. Tus brazos y tu mirada, tus labios y tus piernas, son capaces de decir la convicción que puedas construir en tu cabeza. Venceremos. Con decisión e inteligencia para aislar a los avaros. Claro que venceremos. $(15 / 7 / 16)^{18}$

En algunos posteos el consumo de la telenovela llegó a equipararse con un ritual militante "[a La leona] la milité toda", dice un integrante de Resistiendo... que confiesa no haber visto ninguna desde Rolando Rivas, taxista, o sea, hace más de cuarenta años.

El hecho de que la telenovela ya estuviera escrita en su totalidad antes de la emisión y no obstante pudiera encontrarse en su guion lo que parecía una alusión constante a la actualidad hizo que se le adjudicara un carácter premonitorio, que fue destacado tanto en el grupo

18 En la telenovela, con el fin de recaudar fondos, los obreros deciden publicar un calendario con fotos de ellos mismos desnudos, en algunos casos con consignas político-sindicales escritas en la piel o en carteles. 
Resistiendo... como en el perfil de Pablo Lago, uno de los guionistas, o en publicaciones independientes de espectadores en Twitter:

\#LaLeona qué triste el remate, ${ }^{19}$ triste y actual, cada capítulo parece escrito un día antes de pasarlo. (12/7/16)

Esta mirada hacia el texto en clave política también puede leerse en los comentarios publicados en respuesta a publicaciones de Pablo Lago:

Lunes. Vuelvo a ver a emocionarme y llorar con La leona. Ese último capítulo. Una y mil veces gracias. También digo Gracias a la vida. La lucha y la esperanza van de la mano. No hay otra. Los extraño. Y una vez más. Gracias por el aprendizaje. (18/7/16)

En este último mensaje también puede leerse otro aspecto que estos lectores "políticos" de La leona destacaron en el texto: se lo piensa como portador de un mensaje que puede "aprenderse", sea cuál sea la interpretación que se le dé. Para el grupo Resistiendo.., la enseñanza es cómo enfrentar la lucha general contra el neoliberalismo, encarnado en el gobierno de Mauricio Macri. En el caso de los comentarios de los lectores de La Izquierda Diario, se destaca que la telenovela "enseñó" cuestiones puntuales de la lucha sindical: cómo enfrentarse a la patronal, los pasos que deben seguir los que quieren crear una cooperativa, cómo acercar un proyecto a un legislador, etc. ${ }^{20}$

Por último, es preciso remarcar que las distinciones que se trazaron en el presente análisis entre el peso mayor o menor del marco genérico o bien de las posiciones ideológico-políticas en las evaluaciones publicadas en diferentes plataformas simplemente marcan tendencias generales. Por ejemplo, contradiciendo esta predominancia, en el grupo

19 Con lo del "remate", el posteo se refiere al capítulo emitido el 11/7/16, en el que los trabajadores, ya constituidos en cooperativa, se encuentran con que la fábrica va a ser sorpresivamente rematada, antes de que se trate la expropiación en la legislatura. Un capítulo después, la audiencia se entera de que el remate no tendrá lugar.

20 En este sentido, el mensaje se acercó por momentos al llamado merchandising social en las telenovelas brasileñas, sobre todo de Rede Globo, recurso que consiste en insertar mensajes sociales (por ejemplo sobre donación de órganos) en las tramas. Sobre este punto véase Mazziotti, 2006b. 
cerrado de fans o en los comentarios a la fan page pueden encontrarse también afirmaciones políticas:

[en referencia a la toma de la fábrica Cinpal] La leona ...cualquier similitud con hechos reales es pura coincidencia...Cinpal...ayer me acorde mas q nunca de vos Leona (Fan Page La leona, 27/7/16)

Lamentablemente recién ahora los descubro... y pensar que no tenía a nadie con quien comentar la novela... sin contar con que en este país la grieta nos enfrenta demasiado, y he leído tanta crítica destructiva...

Creo que la novela ha sido un gran mensaje para los que amamos nuestra patria y trabajamos día a día para salir adelante... A mí me ha dejado ganas de empezar algo nuevo en mi vida, algo que sirva a otros, con la convicción de que la honestidad, la pasión y la lucha pueden lograrlo, aunque uno sea un poco débil y las circunstancias no ayuden...

Me encantó y me identificó el mensaje de la Antonópulos diciendo Leoneras y Leoneros germinando... Ojala así sea por el bien de todos! (Grupo cerrado de Facebook La leona, 19/7/16)

En este último mensaje, la dimensión didáctica antes mencionada resurge enaltecida ya como inspiradora de una nueva vocación de compromiso.

\section{A modo de conclusión}

El caso de La leona y su circulación fuera de la pantalla televisiva a través de posteos a favor o en contra permitió comprobar una vez más que la telenovela es un género que integra diferentes niveles de lectura o apropiación. Por un lado, estuvieron aquellos que siempre lo habían consumido y por lo tanto estaban al tanto de sus detalles de factura, de su evolución, de las modalidades de actuación. En la memoria de este sector, La leona tomaba su lugar en el conjunto "telenovela", ya integrado por títulos, actores y actrices, autores, escenas inolvidables atesoradas en sus trayectorias de fans. El texto, desde esta posición, se evaluaba en tanto exponente de un género amado. 
En otra zona de la platea, estaban aquellos para los que La leona era o bien un texto de denuncia o bien una alegoría de la lucha contra el neoliberalismo salvaje. El lugar que ocupaba en este caso lo ubicaba en compañía de discursos diversos, pero sobre todo de naturaleza política o sindical.

Ambos sectores consideraban a La leona tanto en su carácter de texto como de producto, pero en un caso pesaba la trayectoria de los productores en el género, mientras que en el segundo la mirada recaía sobre su trayectoria política.

Sin embargo, a pesar de que las interpretaciones manifestaron notorias diferencias, puede arriesgarse como hipótesis que lo que tal vez mancomune ambas miradas es la socialización, en todos los casos, en lo que algunos consideran la matriz cultural más importante en América latina: el melodrama. El melodrama, como han señalado ya tantos, excede los géneros para convertirse en una verdadera matriz cultural21 ${ }^{21}$ la lógica bipolar y excesiva del melodrama no sólo atraviesa géneros que tradicionalmente han sido asociados con su desmesura, como la telenovela, el bolero, el corrido, sino también zonas que suelen olvidarse como el discurso religioso, el periodístico o el político.

El melodrama no sólo sobrevive en la ironía de los memes, puede aún resurgir desde las entrañas de telenovelas como La leona para activar en la memoria de los espectadores argentinos recuerdos de innumerables tramas en las que los pobres mostraban su estatura moral superior frente a los fríos y desalmados ricos y poderosos, y podían así derrotarlos. Tal vez sea más necesario que nunca, en los tiempos en que vivimos, soñar con que esto es posible.

21 Jesús Martín-Barbero ha sido quien más desarrolló el concepto de matriz cultural, con el melodrama como matriz latinoamericana por excelencia, pero como él mismo ha señalado, los estudios de Carlos Monsiváis (1988, 2006 entre otros) han sido pioneros en este sentido. Para un análisis específico del concepto: Cruces (2008). 


\section{Referencias}

BORDA, L. Bettymaníacos, luzmarianas y mompirris: el fanatismo en los foros de telenovelas latinoamericanas. 2012. Tese (doutorado em Ciências Sociais) - UBA, Buenos Aires, 2012.

BOURDIEU, M. V. Nuevos estilos en la telenovela argentina. Justicia, ética y protagonismo masculino. In: CONGRESO PANAMERICANO DE COMUNICACIÓN, IV, 2008. Anais... [s. l.], 2008. Mimeo.

CRUCES, F. Matrices culturales: pluralidad, emoción y reconocimiento. Anthropos, n. 219, p. 173-179, 2008.

GIMÉNEZ, N. Una leona que le puso el cuerpo a un género difícil. Ámbito Financiero, 18 jul. 2016. Disponível em: http:/www.ambito.com/diario/847406-una-leona-que-lepuso-el-cuerpo-a-un-genero-dificil. Acesso em: 20 jul. 2016.

IRIBARREN, M. Una historia de amor y luchas sociales. Tiempo Argentino, Buenos Aires, 20 jan. 2016.

JOHNSON, D. Fan-tagonism: factions, institutions, and constitutive hegemonies of fandom. In: GRAY, J.; SANDVOSS, C.; HARRINGTON, L. (Eds.). Fandom: identities and communities in a mediated world. Nova York: Londres: New York University Press, 2007. p. 285-300.

MAZZIOTTI, N. Intertextualidades en la telenovela argentina: melodrama y costumbrismo. In: (Org.). El espectáculo de la pasión. Buenos Aires: Colihue, 1993. p. 153-162.

. La industria de la telenovela. La producción de ficción en América latina. Buenos Aires: Paidós, 1996.

La venganza de Montecristo y la máquina novelesca. Tram[p]as de la Comunicación y la Cultura. La Plata: Facultad de Periodismo y Comunicación Social de la UNLP, n. 47, p. 60-64, 2006a.

Telenovela: industria y prácticas sociales. Bogotá: Grupo Editorial Norma: Enciclopedia Latinoamericana de Sociocultura y Comunicación, 2006b.

MONSIVÁIS, C. Escenas de pudor y liviandad. Cidade do México: Grijalbo, 1988.

. Se sufre porque se aprende. (De las variedades del melodrama en América latina). In: DUSSEL, I.; GUTIÉRREZ, D. (Orgs.). Educar la mirada. Políticas y pedagogías de la imagen. Buenos Aires: Manantial: Flacso: Osde, 2006.

RESPIGHI, E. Un culebrón nacional y popular. Páginal2, 20 jan. 2016. Disponível em: http://www.paginal2.com.ar/diario/suplementos/espectaculos/8-37784-2016-01-20. html. Acesso em: 20 fev. 2016.

RIVERO, E. Crisis en la industria de la ficción televisiva: cambios en las audiencias, ficción extranjera y nuevo rol del estado. In: LA IMAGEN IMAGINADA 3. Diálogos sobre ficción seriada en los territorios nacionales, 2017, Córdoba. Anais... Córdoba: Universidad Nacional de Villa María, 25-27 out. 2017. 


\section{Sobre la autora}

Libertad Borda - Doctora en Ciencias Sociales (UBA). Profesora do Departamento de Artes Audiovisuales, UNA.

Data de submissão: 12/12/2018

Data de aceite: 19/02/2019 